\title{
Meio ambiente como um valor cosmopolita: uma análise sócio-histórica comparada no currículo escolar de biologia ${ }^{1}$
}

\author{
Luiza Maria Abreu de Mattos² \\ ORCID: 0000-0002-6039-6938 \\ Maria Margarida Gomes ${ }^{3}$ \\ ORCID: 0000-0002-8609-3898
}

\section{Resumo}

0 trabalho apresenta uma proposta de análise baseada em teorizações a respeito de sistemas comparados de razão, cosmopolitismo e história das disciplinas escolares, na qual se busca entender como determinados objetos se tornam passíveis de reflexão e ação no currículo escolar em uma perspectiva internacional. Comparando-se aspectos históricos do ensino de Biologia no Brasil e na Alemanha, discute-se como o meio ambiente vem constituindose como um valor cosmopolita no currículo escolar dessa disciplina. Em termos teóricometodológicos, documentos curriculares e livros didáticos são tratados como fontes históricas e sua análise articula-se com resultados da revisão de literatura, evidenciando como diferentes organizações culturais cruzam-se para dar inteligibilidade a esse objeto no tempo presente. As análises indicam um processo transnacional de hegemonização do valor meio ambiente de macrotendência pragmática, relacionado ao conceito de educação para o desenvolvimento sustentável. Essa tendência é atravessada pelas tradições curriculares de ensino de diversas formas, assim como pelas questões locais de cada país ligadas à história dessa disciplina escolar. Na Alemanha, as hibridizações referemse, sobretudo, a um predomínio da macrotendência pragmática, pontuado por elementos críticos. Já no Brasil, as macrotendências transnacionais hibridizam-se com características locais principalmente por meio do desenvolvimento acadêmico do campo da Educação Ambiental e suas diferentes correntes, além de aproximações com movimentos ambientais e sociais. 0 trabalho evidencia como tal proposta de análise amplia as potencialidades de articulação entre estudos curriculares e educação comparada, principalmente no sentido do questionamento de consensos internacionais cosmopolitas considerados universais e transcendentais acerca do ensino.

\section{Palavras-chave}

Currículo - Educação comparada - Meio ambiente.

1- 0 presente trabalho foi realizado com apoio da Coordenação de Aperfeiçoamento de Pessoal de Nível Superior - Brasil (CAPES) - Código de Financiamento 001.

2- Escola Alemã Corcovado - Deutsche Schule, Rio de Janeiro, RJ, Brasil. Contato: luizamattos2@gmail.com.

3- Universidade Federal do Rio de Janeiro, Rio de Janeiro RJ, Brasil. Contato: margaridaplgomes@gmail.com. 


\section{Environment as a cosmopolitan value: a comparative socio-historical analysis of the school biology curriculum*}

\section{Abstract}

This work presents an analysis proposal based on theorizations regarding comparative systems of reason, cosmopolitanism and the history of school disciplines, seeking to understand how certain objects become subject to reflection and action in the school curriculum from an international perspective. Comparing historical aspects of the teaching of biology in Brazil and Germany, the article presents a discussion of how the environment has increasingly been constituted as a cosmopolitan value in the biology school curriculum. In theoretical and methodological terms, curricular documents and textbooks are treated as historical sources and an analysis of them is articulated with results of a literature review, evidencing how different cultural organizations are combined to make this object intelligible in the present. The analyses indicate a transnational process of hegemonizing the value of the environment as a pragmatic macro-trend related to the concept of education for sustainable development. This trend is overlapped by curricular traditions of teaching in diverse forms, and also by local issues in each country linked to the history of this school subject. In Germany, the hybridizations refer above all to the pragmatic macro-trend, punctuated by critical elements. Meanwhile, in Brazil, the transnational macro-trends are hybridized with local characteristics, mainly through academic development in the field of environmental education and its different currents, in addition to growing closer to social and environmental movements. The work demonstrates that this proposal for analysis broadens the potentials of articulation between curricular subjects and comparative education, principally in the sense of questioning international consensuses that are considered universal and transcendental concerning education.

\section{Keywords}

Curriculum - Comparative education - Environment.

\section{Introdução}

Neste trabalho, apresentamos o desenvolvimento de uma proposta de análise que amplia as potencialidades de articulação entre estudos curriculares e educação comparada. Sustentamos que investigar consensos internacionais a respeito de valores considerados cosmopolitas, universais e transcendentais no currículo escolar - como é o caso do tema meio ambiente no ensino da disciplina escolar Biologia - é uma contribuição potente para a compreensão dos processos de construção desses conhecimentos. 
A partir da articulação entre teorizações a respeito de sistemas comparados de razão e cosmopolitismo de Thomas Popkewitz (2000, 2008, 2012a, 2012b, 2014, 2017) e estudos curriculares sobre a história das disciplinas escolares de Ivor Goodson (1983, 1990, 1995, 1997), a comparação entre diferentes países, nessa perspectiva, possibilita tornar visíveis aspectos históricos, em contextos distintos, que geram princípios percebidos como transnacionais no ensino. Ao buscar entender relações globais e locais, assim como hibridizações ${ }^{4}$ entre as tendências transnacionais e as questões regionais específicas, em um contexto que considera as relações entre conhecimento, poder e práticas educacionais, a estratégia de um estudo comparado aqui proposta tem como objetivo compreender como diferentes padrões e princípios históricos tornam determinados objetos passíveis de reflexão e ação no currículo escolar em uma perspectiva internacional.

Assim, concebendo a escola como um projeto histórico que gera múltiplas trajetórias e não se restringe às barreiras das nações, estamos considerando que tais hibridizações são produzidas com base em diálogos transculturais, como processos multidirecionais, nos quais as diferenças são compreendidas como potencialidades e não como contínuos de valores hierarquizados (POPKEWITZ, 2017, p. 16).

Em diálogo com as teorizações curriculares de Ivor Goodson, partimos da concepção de que o currículo é uma construção social, que tem evolução sócio-histórica, constituindose como terreno de contestação, fragmentação e mudança (GOODSON, 1997, p. 27). Dessa forma, é resultado tanto do que é formalmente legislado, como de todos os processos de interpretação, subversão e transformação que definem o que conta como conhecimento válido e legítimo e que estão em diálogo permanente com questões internacionais e locais, gerando processos de hibridização.

0 trabalho está organizado de maneira que, primeiramente, situamos a perspectiva de educação comparada adotada no contexto do campo de forma mais ampla. Em seguida, discutimos aspectos centrais da articulação teórica desenvolvida para a construção da proposta de análise aqui apresentada. Por fim, como forma de exemplificar as possibilidades e potencialidades de tal proposta, trazemos um breve resumo de um trabalho desenvolvido sob essa perspectiva (MATTOS, 2019), especificamente a respeito do tema meio ambiente no currículo escolar de Biologia no Brasil e na Alemanha.

\section{A perspectiva do cosmopolitismo na educação comparada}

Desde seu surgimento, no início do século XIX, o campo da educação comparada vem constituindo-se em conflito entre duas correntes portadoras de tradições acadêmicas, culturas políticas e projetos científicos distintos: uma vinculada à necessidade de informar a decisão política, de finalidade pragmática, e outra de caráter acadêmico, que busca

\footnotetext{
4- Para Popkewitz (2000, p. 04), a utilização do conceito globalização/regionalização deve ser feita como um conceito único, que apresenta sobreposição de múltiplas dimensões, vista pelo autor através da hibridização ou amalgamação de práticas educacionais. Através de complexos padrões que são múltiplos e multidirecionais, diferentes camadas de discursos que unem o global e o local se sobrepõem gerando hibridizações, definidas a partir das "interrelações de processos de globalização e regionalização constituídas através de padrões fluidos, múltiplos e historicamente contingenciais" (POPKEWITZ, 2000, p. 06, tradução nossa).
} 
estabelecer a ciência da educação comparada (SCHRIEWER, 1992, p. 31-32). A tensão entre essas duas sensibilidades e os conflitos de interesse e ambiguidades dela decorrentes atravessam e marcam a história da educação comparada.

Parece ser um consenso entre autores que investigam o campo que esse passa atualmente por um momento de diversificação, ao mesmo tempo em que interrogações acerca de sua identidade são levantadas (COWEN; KAZAMIAS; ULTERHALTER, 2012; NÓVOA, 2009; NÓVOA; YARIV-MASHAL, 2003). Desde o final do século XX, a metodologia comparada clássica enfrenta diversos desafios. Unidades de análise largamente inquestionáveis usadas na pesquisa comparada - nações, sociedades, culturas - vêm perdendo sua definição empírica e lógica e vêm sendo colocadas em xeque pelo complexo entrelaçamento das unidades socioculturais e interdependências globais (SCHRIEWER, 2009).

As formas como os principais autores comparatistas têm lidado com essas questões têm se mostrado bastante variadas. Nóvoa (2009) refere-se a diversos grupos de comunidades discursivas presentes no campo, que se diferenciam, principalmente, por assumir perspectivas que se aproximam mais de teorias funcionalistas (baseadas na ideia de equilíbrio social) ou críticas (fundadas na ideia de mudança social) e por adotar abordagens que apresentam tendências ora mais descritivas - baseadas em fatos e fenômenos observáveis considerados como realidades naturais - ora mais conceituais - que consideram os fatos como realidades construídas por discursos que os situam em determinado espaço-tempo (NÓVOA, 2009, p. 38).

Neste trabalho, dialogamos com uma perspectiva sócio-histórica da educação comparada, que se situa em uma vertente crítica com abordagens conceituais, baseada principalmente em Thomas Popkewitz (2000, 2012a, 2012b, 2017). A ideia central é que a comparação se dá por meio da análise do sentido histórico dos fatos, com base no questionamento dos princípios epistemológicos da modernidade. Popkewitz (2000) desenvolve uma estratégia comparativa para entender relações globais e nacionais/locais e os sistemas híbridos de razão a partir da relação entre conhecimento, poder e práticas educacionais, entendendo que a escola tem um papel fundamental na construção da concepção de sujeito cosmopolita. Para o autor, os sistemas de razão - ou conhecimento - são os princípios que, historicamente, definem o que é pensado, conhecido e sobre o que atuamos em diferentes tempos/espaços, portanto, os sistemas por meio dos quais os objetos da educação são produzidos e administrados (POPKEWITZ, 2012a, 2012b).

Para esse autor, as qualidades comparadas do sistema racional de educação são abordadas por meio da noção de cosmopolitismo, que, nesse contexto, expressa uma tese cultural acerca do sujeito compreendido como agente, cuja razão e racionalidade científica poderiam intervir no desenvolvimento da vida cotidiana e da sociedade em nome do progresso humano. Tal tese refere-se atualmente ao que se diz acerca do cosmopolitismo no contexto do aprendiz permanente e da sociedade da aprendizagem. A educação moderna vincula constantemente o indivíduo a relatos de progresso social ou econômico e de revitalização da democracia que promoverão o aprimoramento pessoal. A nação é interpretada de várias maneiras e a aprendizagem permanente atua como um projeto particular para a construção de um governo transnacional. A resolução de problemas, como uma característica inerente à vida, é um discurso dominante que atravessa as fronteiras 
nacionais para reformular o espaço educacional em uma comunidade imaginada, na qual o conhecimento é uma chave para a competitividade industrial e o emprego.

Nessa perspectiva, a imagem da comunidade transnacional é de uma regulamentação sobre a homogeneidade cosmopolita, orientada para o futuro, e não mais como ocorria anteriormente com a identidade nacional legitimada e enraizada em histórias, culturas e territórios antigos. Seus princípios universais referem-se a saberes abstratos, direitos humanos, democracia, progresso e igualdade, ignorando os conflitos e divisões por meio dos quais o consenso e a paz são celebrados e remodelados. 0 cosmopolitismo serve de ferramenta intelectual para pensar em termos históricos e comparativos as escolas como lugares que conectam a individualidade com o pertencimento coletivo; destaca teses culturais para considerar princípios gerados sobre modos de vida na política, reforma e pesquisas pedagógicas.

0 universalismo das teses culturais a respeito do cosmopolitismo da criança fornece um conjunto aparentemente transcendente de valores que define o que é provinciano e o que é passado. Popkewitz (2012a) aponta que essa transcendência se expressa, por exemplo, nas políticas e na pesquisa contemporânea da Europa e da América do Norte, que se referem à educação para todas as crianças, como se a palavra todas representasse uma unidade esclarecida que transcende as diferenças humanas. No entanto, o significado de todo da humanidade não é universal, mas histórico e particular e envolve exclusões e processos de aviltamento que situam algumas qualidades das pessoas, colocando-as fora dos espaços da razão e da inclusão. Assim, o foco em teses culturais acerca do cosmopolitismo na educação é uma ferramenta histórica comparada para diagnosticar o sistema de razão por trás da geração de princípios que diferenciam e dividem (POPKEWITZ, 2008).

Nesse sentido, a comparação permite-nos tornar visíveis as diferenças históricas no tempo e no espaço entre os princípios gerados sobre quem somos, quem deveríamos ser e quem não somos. Tal estratégia, de estudo comparado, é chamada de epistemologia social. Sua função seria estudar os sistemas de razão para localizar diferentes maneiras de pensar e agir, através da compreensão do político no ensino (POPKEWITZ, 2012b). Estudar o sistema de razão no ensino, ou sua epistemologia social, significa considerar o conhecimento como algo historicamente situado, relacional e socialmente embutido com o político. A epistemologia social considera diferentes padrões e princípios históricos em diferentes tempos e espaços que tornam determinados objetos passíveis de reflexão e ação. Ou seja, é uma abordagem que permite investigar o que nós sabemos, considerando que como descrevemos o mundo não é natural, mas passa por interesses sociais. 0 foco no cosmopolitismo, nesse contexto, é duplo. Por um lado, evidencia as características históricas importantes que dão forma e moldam os princípios epistemológicos por meio dos quais os princípios da pedagogia no ensino moderno são ordenados, distinguidos e diferenciados. Por outro lado, o cosmopolitismo serve de ferramenta intelectual para pensar um método comparado que se refere à heterogeneidade dos sistemas de razão no ensino moderno e suas ciências. As condições, regras e padrões da razão variam historicamente, levando a diferentes comparações. A epistemologia social, nesse caso, tem a função de estudar os sistemas de razão para localizar diferentes maneiras de pensar e de agir. 
Nesse sentido, a historicização é concebida não como a busca pelas origens ou pela evolução de algo, mas sim como um entendimento acerca de como os objetos do presente tornaram-se plausíveis e viáveis por meio de diferentes práticas históricas (POPKEWITZ, 2012c, p. 15). Tais práticas desconectam-se de suas origens e se reconectam formando tramas mais complexas do que as somas de suas partes, que geram as possibilidades do presente, com aberturas para mudanças e resistências. Assim, ao tratar da história dos currículos escolares, Popkewitz o faz a partir da abordagem da história do presente, propondo tornar visíveis as regras e padrões da razão, com base em princípios epistemológicos, com o objetivo de questionar como é possível pensar no presente e na forma como as coisas são concebidas como uma questão histórica (POPKEWITZ, 2017, p. 16). A tarefa da história do presente é, portanto, considerar o sistema de razão que ordena e classifica o que é visto, discutido e feito no ensino escolar.

Entendendo as redes de práticas por meio das quais os objetos do ensino escolar ganham inteligibilidade, os princípios que ordenam e classificam o currículo escolar são reunidos, conectados e desconectados através de complexos processos históricos (POPKEWITZ, 2011, p. 2). Portanto, é por meio do currículo que as regras e padrões da razão e da pessoa razoável incorporam princípios que governam o que deve ser conhecido e como esse aprendizado deve ocorrer. É preciso, portanto, que a história e o estudo do currículo se centrem nas descontinuidades, desenraizando as fundações tradicionais dos assuntos escolares, justamente naquilo que lhes é considerado natural ou senso comum.

Assim, uma história da educação comparativa e transnacional possibilita uma importante forma de pensar a escola contemporânea como um projeto histórico que gera múltiplas trajetórias (POPKEWITZ, 2017, p. 16). A questão teórica colocada é como as diferenças são produzidas, com base em uma concepção de diálogos transculturais, sob a perspectiva da história do tempo presente e do sistema de razão do cosmopolitismo.

\section{A educação comparada e as tradições curriculares}

A visão dos currículos escolares como derivados do melhor trabalho de especialistas atuando como iniciadores das tradições acadêmicas é, geralmente, aceita tanto por educadores quanto por leigos. Tal visão é sustentada por porta-vozes governamentais, agências educacionais, associações disciplinares e pela mídia. É, portanto, uma visão de consenso, que as disciplinas escolares derivam das disciplinas intelectuais ou formas de conhecimento (posteriormente ampliados para campos de conhecimento) criadas e sistematicamente definidas por uma comunidade de estudiosos (GOODSON, 1990, p. 233-234). No entanto, a análise mais atenta dos processos históricos, a partir dos quais as disciplinas escolares surgem, são definidas e se estabelecem, revela uma série de disparidades entre explicações que buscam legitimar a tradição acadêmica das disciplinas escolares e os processos históricos de evolução dessas. 0 fato de as disciplinas comumente evoluírem para o estabelecimento de uma base acadêmica não explica quais são as forças que empurram as disciplinas nessa rota e culminam nesse padrão (GOODSON, 1990). Não podemos assumir que toda matéria escolar que estabelece uma base acadêmica o faz com relação direta a um campo de conhecimento acadêmico pré-estabelecido. Há 
disciplinas escolares que precedem, são divorciadas ou simplesmente não têm uma disciplina acadêmica-base, formando comunidades autônomas. Além disso, o contexto escolar abrange diversos aspectos que o diferenciam do contexto universitário, como problemas de motivação e controle dos alunos.

Para Goodson (1990), de acordo com Layton (1972), com frequência, a origem de uma matéria escolar relaciona-se aos interesses dos alunos e à aplicabilidade de tal conhecimento a suas necessidades. Nesse estágio inicial, as disciplinas geralmente não apresentam professores com treinamento especializado naquilo que ensinam e se baseiam no entusiasmo missionário desses pioneiros. No entanto, à medida que a matéria avança, para se tornar merecedora de recursos financeiros e oportunidades de carreira, ela precisa empregar discursos que possibilitem que esta seja considerada disciplina acadêmica, aproximando-se das disciplinas universitárias. Layton definiu três estágios dessa evolução, relacionados a finalidades utilitárias e pedagógicas, que geralmente predominam no processo de emergência de uma disciplina escolar, e a finalidades acadêmicas, relacionadas à aproximação das ciências de referência das universidades, o que tende a ocorrer ao longo do processo de consolidação das mesmas. A ocorrência de diálogos e oscilações temporais de forma não linear entre essas tradições de ensino de natureza utilitárias, pedagógicas e acadêmicas abordadas no modelo de Layton tem sido apontada por diversos autores no ensino de Ciências e de Biologia no Brasil (GOMES; SELLES; LOPES, 2013; FERREIRA; GOMES; LOPES, 2001; MARANDINO; SELLES; FERREIRA, 2009; SELLES; FERREIRA, 2005). Por exemplo, Gomes, Selles e Lopes (2013) apontam que:

\begin{abstract}
A linearidade histórica desse modelo torna-o limitado para interpretações que atentem para a variedade de espaços sociais e institucionais em que as disciplinas escolares tomam forma. Considerando tal limitação, a ideia de oscilação temporal entre as tradições utilitárias, pedagógicas e acadêmicas proposta por Lopes (2000) e Selles e Ferreira (2005) parece ser uma forma mais abrangente de explicar as transformações históricas pelas quais passam as disciplinas. Lopes (2000), ao analisar o currículo de Ciências no Colégio de Aplicação da Universidade Federal do Rio de Janeiro (UFRJ) entre 1969 e 1998, aponta uma trajetória que mescla, de forma não linear, as tradições utilitárias, pedagógicas e acadêmicas. Da mesma forma, Selles e Ferreira (2005) sugerem que os conteúdos de ensino da disciplina escolar Biologia relacionados ao tema da reprodução humana, apesar de fortemente vinculados a finalidades de natureza acadêmica, vêm sendo também selecionados a partir de finalidades de caráter utilitário e pedagógico. (GOMES; SELLES; LOPES, 2013, p. 480).
\end{abstract}

Assim, a partir do diálogo com essa perspectiva teórica, a proposta de análise aqui apresentada busca investigar de que maneira objetivos pedagógicos, utilitários e acadêmicos vêm informando a inserção de objetos no currículo escolar, articulando tal investigação com a perspectiva comparativa de Thomas Popkewitz, centrada no sistema comparado de razão e na noção de cosmopolitismo.

Com a busca de articular esses dois autores, baseamo-nos em trabalhos como Ferreira (2014), Ferreira e Jaehn (2010), Jaehn e Ferreira (2012) e Jaehn, (2012), ao assumir que as aproximações e os distanciamentos dessas duas vertentes não as colocam em 
"polos contraditórios ou opostos, mas em um horizonte de possibilidades de articulações" (JAEHN; FERREIRA, 2012, p. 268). Tais diálogos referem-se, principalmente, a noções de história, epistemologia e currículo que vêm circulando e se hibridizando nos escritos brasileiros (FERREIRA; JAEHN, 2010). Ao apostar em uma lente teórica pautada nas duas perspectivas de História do Currículo, a história social de Goodson e a epistemologia social de Popkewitz, Jaehn e Ferreira (2012) buscam entrecruzar visões distintas de poder com base nesses dois autores. A partir da busca por aproximações entre abordagens críticas, pós-modernas e pós-estruturalistas, as autoras desenvolvem tal movimento para subsidiar investigações que abordem, simultaneamente, os aspectos históricos e contingentes da escolarização. Ferreira (2014, p. 188) sustenta, portanto, que os dois autores, ainda que em perspectivas teóricas diversas:

[...] se interessam pelos contextos externos e internos da escolarização, assumindo como central as relações entre conhecimento e poder, que produzem os currículos e as disciplinas. Assim, ainda que mais voltados para as estruturas sociais que constituem o que Goodson (1995, p. 84) denomina de "forma curricular", ou então para os aspectos produtivos do poder que regulam as subjetividades (POPKEWITZ, 1994, 1997, 2001) ambas as perspectivas são produtivas para problematizar currículos hegemonicamente posicionados [...]. (FERREIRA, 2014, p. 188).

Assim, nessa perspectiva, os currículos são compreendidos "como construções sóciohistóricas que produzem e hegemonizam significados sobre o que somos e o que sabemos". Os conhecimentos passados nas disciplinas escolares configuram-se como formas de regulação social, que participam de lutas e relações de poder "em torno das definições de quais conhecimentos e racionalidades devem ser considerados válidos socialmente" (FERREIRA, 2014, p. 187).

Portanto, concordando com essas autoras, assumimos neste trabalho que olhar para o currículo com base nas teorizações de Ivor Goodson permite-nos travar articulações com as discussões de Thomas Popkewitz sobre epistemologia social, cosmopolitismo e sistema comparado de razão. Assim, juntamente com Ferreira (2014, p. 206), entendemos que é preciso investigar o currículo a partir da compreensão das "razões sócio-históricas de assumirmos determinados discursos como válidos e/ou verdadeiros" e que olhar para o currículo dessa forma se mostra um caminho potente. Por meio da investigação dos processos históricos e descontinuidades, busca-se desnaturalizar a presença de determinados objetos no currículo escolar, tornando visíveis tanto os princípios epistemológicos que os tornam parte do ensino moderno, como diferentes condições, regras e padrões que fazem parte desses sistemas de razão.

Ao assumir tal perspectiva, trazemos elementos de um estudo desenvolvido em tese de doutorado (MATTOS, 2019) a respeito de como o tema meio ambiente pode ser compreendido enquanto objeto de ensino que toma parte do sistema de razão que constitui o cosmopolitismo contemporâneo no currículo escolar de Biologia. Apresentamos, a seguir, alguns aspectos centrais de tal estudo, como forma de ilustrar a proposta de análise desenvolvida. 


\section{O meio ambiente como valor cosmopolita}

0 referido trabalho (MATTOS, 2019) apresenta um estudo comparado sobre o tema meio ambiente no currículo escolar da disciplina Biologia em dois países, Brasil e Alemanha, argumentando como esse vem constituindo-se como um valor cosmopolita. Ao articular teorizações a respeito de cosmopolitismo e sistemas de razão de Thomas Popkewitz e estudos curriculares sobre a história das disciplinas escolares de Ivor Goodson, busca-se explicar como as macrotendências transnacionais sobre o meio ambiente crítica, pragmática e conservacionista ${ }^{5}$ - relacionam-se com as tradições curriculares acadêmica, pedagógica e utilitária no ensino escolar de Biologia.

Assim, a partir de uma abordagem analítica comparada, focada na história do presente, documentos curriculares e livros didáticos são tratados como fontes históricas e sua análise articula-se com resultados da revisão de literatura na busca por compreender como práticas históricas transnacionais e regionais se cruzam para dar inteligibilidade a esse objeto, ou seja, o tornam possível, viável e inteligível no tempo presente. Articulase, portanto, analiticamente essas fontes em uma perspectiva histórica que procura desnaturalizar o que é apresentado sobre o tema meio ambiente no contexto do currículo de Biologia.

Busca-se, assim, construir uma forma de análise comparativa que permite dar visibilidade a diferenças produzidas historicamente a respeito do tema no Brasil e na Alemanha. A integração da análise desse conjunto de fontes possibilita reconhecer diferentes formas de pensar e agir relacionadas ao tema meio ambiente. Evidencia-se assim os sistemas de razão híbridos a partir da relação entre conhecimento, poder e práticas educacionais. Para isso, são mobilizados os documentos curriculares oficiais considerados historicamente mais relevantes, de acordo com a literatura da área, e os livros didáticos mais utilizados em cada país nos últimos anos. Tais materiais são tratados como fontes históricas e sua análise, articulada com resultados da revisão de literatura, evidencia como diferentes organizações culturais se cruzam para dar inteligibilidade a esse objeto no tempo presente.

0 estudo indica que o aumento da inserção dos temas ambientais, nos espaços curriculares da disciplina escolar Biologia nos últimos anos, é amplamente reconhecido por autores desse campo e que a articulação entre questões educacionais e sociais e interesses científicos tem sido um fator essencial para esse processo (GOMES, 2008; GOMES; SELLES; LOPES, 2013;

\footnotetext{
5- Layrargues e Lima (2014) definem três macrotendências que formam os principais polos das representações contemporâneas relacionadas às propostas políticas, pedagógicas e epistemológicas sobre o meio ambiente no contexto do ensino: "conservacionista", relacionada à ideia de proteção da natureza e ao comportamentalismo, baseada na sensibilização através de atividades na natureza e na mudança de comportamentos individuais, se fundamenta em princípios da Ecologia e propõe que o estabelecimento de uma relação individual afetiva com a natureza resultaria em uma mudança cultural de relativização do antropocentrismo que predominou nas primeiras décadas após o surgimento das discussões sobre Educação Ambiental; "pragmática", que se caracteriza por defender um ambientalismo de resultados mercadológicos, com base na hegemonia neoliberal estabelecida mundialmente a partir da década de 1980, sobrepondo a lógica de mercado às esferas sociais, associada a concepções como "economia verde", "mecanismos de desenvolvimento limpo", "diminuição da pegada ecológica" e "uso consciente dos recursos" que se baseiam nos atuais padrões de produção e consumo e operam no nível das mudanças tecnológicas e comportamentais, se apoiando na ideia de que essas modificações superficiais serão suficientes para manter o sistema atual; "crítica", que agrega as correntes que começaram a se desenvolver nos anos 1990 como uma reação à visão conservacionista dominante, baseada na ideia de que a crise ambiental não se trata de problemas naturais, e sim, de problemas sociais que se expressam na natureza, tais correntes defendem que os problemas ambientais se originam nas relações sociais, nos modelos de sociedade e de desenvolvimento dominante.
} 
MENDONÇA; TRAJBER, 2006; OLIVEIRA, 2009; SANTOS, 2010; VASCONCELOS; GOMES, 2011). Embora, originalmente, o campo da Educação Ambiental tenha se configurado como o principal espaço de desenvolvimento das discussões sobre o tema meio ambiente no ensino, desde o final da década de 1980, fala-se também em Educação para o Desenvolvimento Sustentável. A partir de 1992, a Agenda 21 torna-se um dos principais documentos de referência para o tema e o conceito de desenvolvimento sustentável consolida-se internacionalmente. A forma como este é compreendido em diferentes partes do mundo, no entanto, apresenta variações significativas (UNTERBRUNER, 2016, p. 171).

No Brasil, o conceito de desenvolvimento sustentável tem sido motivo de controvérsia e é amplamente criticado por parte dos atores do campo, principalmente, aqueles que se identificam com correntes associadas à macrotendência crítica (LAYRARGUES, 2003; LAYRARGUES; LIMA, 2014; LOUREIR0, 2002). Já na Alemanha, fala-se sobre consensos derivados das diferentes correntes da Educação Ambiental que ao longo da década de 1980 foram consolidados sob o termo "desenvolvimento sustentável" (SCHLEICHER, 1995).

Historicamente, no Brasil, a diversidade de correntes e tendências relacionadas ao ensino do tema meio ambiente na escola vem sendo observada desde a década de 1990 e acentuando-se através de iniciativas de autorreflexão e autoanálise, em especial no campo da Educação Ambiental (SAUVÉ, 2005; LAYRARGUES, 2004; SORRENTINO, 1995). A tendência conservacionista, predominante até a década de 1980 no Brasil, relacionase tanto com a origem do movimento ambientalista ligada à perspectiva da preservação, quanto com o contexto político interno de autoritarismo e restrições democráticas do período militar (LAYRARGUES; LIMA, 2014, p. 27). A abertura política e, consequentemente, a expansão e o aprofundamento dos questionamentos de matriz crítica no país acabaram aproximando as discussões ambientais dos movimentos sociais.

Dessa maneira, passaram a coexistir dentro do debate ambiental brasileiro, e, mais especificamente, dentro do ensino de Biologia, as diversas correntes encontradas até hoje no campo. Os documentos curriculares e políticas educacionais brasileiras refletem esse cenário de heterogeneidade, apresentando concepções que oscilam entre a macrotendência crítica e uma tendência mais conservadora, priorizando em alguns momentos aspectos pragmáticos e técnicos da sustentabilidade e, em outros, enfatizando a preservação da natureza. 0 conceito de desenvolvimento sustentável ora é assumido de forma naturalizada com base em aspectos da macrotendência pragmática, ora problematizado a partir de questionamentos oriundos de uma matriz relacionada à macrotendência crítica.

Na Alemanha, a concepção de desenvolvimento sustentável vem hegemonizando-se associada à perspectiva da macrotendência pragmática de forma mais evidente. As reformas educacionais alemãs ocorridas a partir da década de 1990 parecem ter sido os principais fatores responsáveis por suavizar tal disputa (UNTERBRUNER, 2016). Tais reformas baseavam-se em perspectivas de ensino fundamentadas na experimentação e voltadas para a resolução de situações problema, com base na interdisciplinaridade e em concepções que priorizam dimensões cognitivas, pragmáticas e afetivas do processo de aprendizagem. Assim, a perspectiva do desenvolvimento sustentável - que reunia aspectos como o enfoque nas atitudes e interesses dos alunos e a tomada de decisões e a resolução de problemas ia de encontro às concepções subjacentes às bases da reforma educacional em curso, e, portanto, agregou-se a ela (SCHLEICHER, 1995). Com o desenvolvimento de iniciativas de 
integração dos países da Europa Central, nesse mesmo período, a influência das tendências internacionais passou a ser cada vez mais expressiva nessas reformas curriculares.

Nesse contexto, avaliações internacionais de grande escala como o TIMMS (Trends In International Mathematics And Science Study) e o PISA/OCDE (Organisation for Economic Co-operation and Development Programme for International Student Assessment) tornaram-se aspectos centrais para o Ensino de Biologia na Alemanha (GROPENGIEßER; KATTMAN, 2006, p. 21). As discussões sobre educação para o meio ambiente se voltaram para a noção de competência adotada pelo PISA/OCDE, levando a uma série de ajustes nas concepções de competência que eram discutidas na Alemanha até então (BÖGEHOLZ et al., 2014, p. 235). Dessa forma, a perspectiva da educação para o desenvolvimento sustentável, alinhada a uma macrotendência pragmática, como definida por documentos internacionais - como os Objetivos de Desenvolvimento Sustentável (ODS) desenvolvidos pela ONU/UNESCO ${ }^{6}$ - tornaram-se as principais referências na Alemanha para essa discussão. Por meio de questões pragmáticas como estratégias de investimento na eficiência do sistema de produção atual, de aspectos comportamentalistas relacionados à conservação ou ainda de aspectos críticos como a participação popular e a mobilização política, a tradição curricular de ensino mais valorizada nos materiais alemães pode ser caracterizada como utilitária (MATTOS, 2019).

Ao tomar como exemplo recortes de livros didáticos desses dois países é possível exemplificar de modo mais acurado a produção desse objeto como um valor cosmopolita. A maioria dos livros analisados (MATTOS, 2019), tanto alemães como brasileiros, faz referências a documentos internacionais, destacando o caráter transnacional/ universal do tema meio ambiente. A questão ambiental é colocada como componente indispensável para a sociedade atual, de forma alinhada à concepção de desenvolvimento sustentável associada à macrotendência pragmática, que vem sendo apresentada como modelo transnacional, como exemplificado abaixo:

Gestão ambiental engloba política ambiental, assim como conservação. É a totalidade de todos os esforços e medidas para a proteção do meio ambiente. Sua meta é o desenvolvimento sustentável para a manutenção dos recursos naturais da humanidade. A partir da Declaração da Conferência sobre Meio Ambiente e Desenvolvimento no Rio de Janeiro (1992) a conservação ambiental se tornou componente indispensável do desenvolvimento sustentável. A gestão ambiental é uma tarefa global, regional e local. (BAYRHUBER; HAUBER; KULL, 2010, p. 418, tradução nossa).

Nesse modelo de desenvolvimento, considera-se que o avanço econômico e a conservação do meio ambiente são compatíveis e devem estar intimamente relacionados [...]. Os Objetivos e metas estimularão a ação para os próximos 15 anos em áreas de importância crucial para a humanidade e para o planeta [...]. (LOPES; ROSSO, 2016, p. 132-133).

\footnotetext{
6- Em agosto de 2015, os Objetivos de Desenvolvimento Sustentável (ODS) passaram a ser adotados no contexto da Cúpula das Nações Unidas para o Desenvolvimento Sustentável, com 0 intuito de orientar as políticas nacionais e as atividades de cooperação internacional nos próximos quinze anos, sucedendo e atualizando os Objetivos de Desenvolvimento do Milênio (ODM). Disponível em: http://www.itamaraty.gov.br/pt-BR/ politica-externa/desenvolvimento-sustentavel-e-meio-ambiente/134-objetivos-de-desenvolvimento-sustentavel-ods. Acesso em: set. 2017.
} 
Tais exemplos reforçam, portanto, que nos contextos do Brasil e da Alemanha, a forma como o meio ambiente vem se constituindo como um valor cosmopolita no currículo escolar de Biologia parece estar relacionada a um processo transnacional de hegemonização da macrotendência pragmática, apoiado no conceito de educação para o desenvolvimento sustentável. Porém, essa tendência é atravessada pelas tradições de ensino do currículo escolar de Biologia de diversas formas, assim como por questões locais de cada país, relacionadas à história dessa disciplina escolar. Na Alemanha, as hibridizações referem-se, principalmente, a um predomínio da concepção hegemônica transnacional relacionada ao conceito de desenvolvimento sustentável, baseada na macrotendência pragmática, porém, que apresenta elementos da macrotendência crítica. A rejeição de aspectos comportamentalistas e a inclusão de questões relacionadas às desigualdades socioeconômicas seriam exemplos desses elementos, que parecem estar em grande parte relacionados à tradição didática alemã, como exemplificado no trecho abaixo, retirado de um dos livros analisados.

Graças à influência da Conferência das Nações Unidas sobre Ambiente e Desenvolvimento no Rio de Janeiro em 1992, são analisados aspectos ecológicos, assim como econômicos na avaliação de um produto. [...] Nos últimos anos, passou-se a considerar nessas análises uma terceira dimensão da sustentabilidade, seus aspectos sociais. Assim, verifica-se se na produção e/ou eliminação de um produto lançou-se mão de exploração de mão de obra barata, trabalho infantil e se a utilização do produto pode gerar prejuízos para a saúde. (BRAUN; PAUL; WESTENDORFBRÖRING, 2011, p. 365, tradução nossa).

Já no Brasil, é observada uma oscilação entre as três macrotendências, com presença significativa da macrotendência crítica, ilustrada pelo exemplo abaixo.

Para diminuir os prejuízos ao meio ambiente e, consequentemente, melhorar nossa qualidade de vida, é necessário que se tomem medidas que diminuam o volume do lixo e favoreçam o tratamento adequado dos resíduos. Cabe à sociedade, por exemplo, pressionar o governo a criar e fiscalizar medidas voltadas à proteção do meio ambiente e da saúde da população. Mas há também algumas coisas que você mesmo pode fazer no seu dia a dia:

- Evite usar sacolas plásticas de estabelecimentos para carregar compras. Sempre que possível, utilize sua própria sacola. [...].

- Não jogue lixo na rua. [...].

- Participe de associações de bairro e de movimentos ecológicos para pressionar o governo em todas as questões ligadas à proteção do meio ambiente. (GEWANDSZNAJDER; LINHARES; PACCA, 2016, p. 277 e 287).

Esse quadro parece ser resultado de um processo de hibridização entre macrotendências transnacionais e características locais, tais como: o desenvolvimento acadêmico e o processo autorreflexivo do campo da Educação Ambiental e suas diferentes correntes; a aproximação entre movimentos ambientais e sociais; e o contexto histórico de reabertura política na qual tais discussões se desenvolveram. 


\section{Considerações finais}

A proposta de análise desenvolvida, assim como a análise apresentada apontam caminhos sobre as formas como o currículo escolar vem entrelaçando múltiplos aspectos locais e globais, no processo de globalização/regionalização. A articulação entre macrotendências transnacionais e tradições curriculares gera padrões contingentes e históricos, que envolvem relações entre conhecimento e poder de forma complexa, não unidirecional e que apresenta sobreposição de múltiplas dimensões (POPKEWITZ, 2000, p. 4).

Tal olhar sobre o meio ambiente no ensino escolar de Biologia, com base no cosmopolitismo de Popkewitz (2012a, 2014) e a partir das teorizações de Goodson (1983, 1990, 1995, 1997) sobre a história das disciplinas escolares, possibilita problematizar esse tema, compreendendo sua construção como um valor universal na formação escolar da criança racional, restringindo o possivel a partir da homogeneização de determinadas tendências.

A análise baseada em teorizações acerca de sistemas comparados de razão, cosmopolitismo e história das disciplinas escolares, evidenciou como o meio ambiente vem se constituindo como um valor cosmopolita no currículo escolar de Biologia, a partir da investigação da forma como tradições curriculares vêm informando a inserção desse objeto no currículo escolar, de forma articulada às macrotendências crítica, pragmática e conservacionista relacionadas ao tema. Tomando livros didáticos e documentos curriculares oficiais como fontes históricas, evidencia-se como diferentes organizações culturais cruzam-se para dar inteligibilidade a esse objeto no tempo presente.

Desse modo, tal análise permite mostrar as aproximações entre o tema meio ambiente nos currículos de Biologia no Brasil e na Alemanha, mas também elucida como se dão as interpretações nas construções curriculares desses dois países. Assim, é possível perceber que essa temática é validada internacionalmente por meio da exploração de tendências pragmáticas, associadas à ideia de educação para o desenvolvimento sustentável, que se constituem em meio a tradições curriculares dessa disciplina escolar. Por outro lado, também é importante destacar que na Alemanha tal consenso pragmático e utilitário não deixa de apresentar características de tendências críticas. Já no Brasil, a análise indica a oscilação entre as tendências conservadora, pragmática e crítica, mas com uma forte presença dessa última, inseridas em construções curriculares atravessadas por tradições acadêmicas, pedagógicas e utilitárias.

Concluindo, a análise reforça a argumentação que toma o tema meio ambiente no currículo de Biologia como um valor cosmopolita, produzido social e historicamente a partir da interseção de discussões curriculares relacionadas à valorização de tendências da Educação Ambiental e a tradições curriculares da disciplina escolar Biologia. Ao potencializar esse olhar a partir do estudo comparado e analisando diferentes organizações e conexões culturais que vêm construindo esse sistema de razão, destacam-se suas heterogeneidades, assim como o que está sendo incluído e excluído nessa construção. Tal proposta de análise amplia as potencialidades de articulação entre estudos curriculares e educação comparada, principalmente no sentido do questionamento dos consensos internacionais cosmopolitas considerados universais e transcendentais acerca do ensino. 


\section{Referências}

BAYRHUBER, Horst; HAUBER, Wolfgang; KULL, Ulrich (org.). Linder biologie gesamtband. Braunschweig: Schroedel, 2010.

BÖGEHOLZ, Susanne et al. Education for sustainable development in German science education: pastpresent-future. Eurasia Journal of Mathematics, Science \& Technology Education, London, v. 10, n. 4, p. 231-248, ago. 2014.

BRAUN, Jürgen; PAUL, Andreas; WESTENDORF-BRÖRING, Elsbeth (org.). Biologie heute SII. Braunschweig: Westermann Schroedel, 2011.

COWEN, Robert; KAZAMIAS, Andreas; ULTERHALTER, Elaine (org.). Educação comparada: panorama internacional e perspectivas. v. 1. Brasília, DF: Unesco: Capes, 2012.

FERREIRA, Marcia Serra. Currículo e cultura: diálogos com as disciplinas escolares ciências e biologia. In: MOREIRA, Antonio Flavio; CANDAU, Vera (org.) Currículos, disciplinas escolares e saberes. Petrópolis: Vozes. 2014. p. 185-213.

FERREIRA, Marcia Serra; GOMES, Maria Margarida; LOPES, Alice Casimiro. Trajetória histórica da disciplina escolar ciências no Colégio de Aplicação da UFRJ (1949-1968). Pro-Posições, Campinas, v. 34, n. 12, p. 9-26, 2001.

FERREIRA, Marcia Serra; JAEHN, Lisete. História do currículo: diálogos com Ivor Goodson e Thomas Popkewitz. In: REUNIÃO DA ASSOCIAÇÃO NACIONAL DE PÓS-GRADUAÇÃO E PESQUISA EM EDUCAÇÃO, 33., 2010, Caxambu. Anais... Caxambu: Anped, 2010. Trabalho encomendado (GT Currículo). Disponível em: https://www.fe.unicamp.br/gtcurriculoanped/33RA/trabalhos/MARCIASERRALISETEJAEHN_UFRJ.pdf. Acesso em: abr. 2021.

GEWANDSZNAJDER, Fernando; LINHARES, Sergio; PACCA, Helena. Biologia hoje: ensino médio. v. 3. São Paulo: Ática. 2016.

GOMES, Maria Margarida. Conhecimentos ecológicos em livros didáticos de ciências: aspectos sócio-históricos de sua constituição. 2008. 250 f. Tese (Doutorado em Educação) - Universidade Federal Fluminense, Niterói. 2008.

GOMES, Maria Margarida.; SELLES, Sandra Escovedo; LOPES, Alice Casimiro. Currículo de ciências: estabilidade e mudança em livros didáticos. Educação \& Pesquisa, São Paulo, v. 39, n. 2, p. 477-492, abr./jun. 2013.

GO0DSON, Ivor Frederick. A construção social do currículo. Lisboa: Educa, 1997.

GO0DSON, Ivor Frederick. Currículo: teoria e história. Petrópolis: Vozes, 1995.

GOODSON, Ivor Frederick. School subjects and curriculum change: case studies in curriculum history. London: Croom Helm, 1983. 
GOODSON, Ivor Frederick. Tornando-se uma matéria acadêmica: padrões de explicação e evolução. Teoria \& Educação, Porto Alegre, v. 2, p. 230-254, 1990.

GROPENGIEßER, Harald; KATTMANN, Ulrich (org.). Fachdidaktik biologie / Die biologiedidaktik begründet von Dieter Eschenhagen, Ulrich Kattmann und Dieter Rodi. Köln: Aulis, 2006.

JAEHN, Lisete. Pensamento curricular e a relação entre poder e conhecimento: controle e regulação social. Revista Espaço do Currículo, João Pessoa, v. 4, n. 2, p. 3-9, jan. 2012.

JAEHN, Lisete; FERREIRA, Marcia Serra. Perspectivas para uma história do currículo: as contribuições de Ivor Goodson e Thomas Popkewitz. Currículo sem Fronteiras, v. 12, n. 3, p. 256-272, 2012. Disponível em: http://www.curriculosemfronteiras.org/vol12iss3articles/jaehn-ferreira.pdf. Acesso em: ago. 2019.

LAYRARGUES, Philippe Pomier. A natureza da ideologia e a ideologia da natureza: elementos para uma sociologia da educação ambiental. 2003.100 f. Tese (Doutorado em Ciências Sociais) - Universidade Estadual de Campinas, Campinas, 2003. Disponível em: http://libdigi.unicamp.br/document/?code=vtls000293110. Acesso em: ago. 2017.

LAYRARGUES, Philippe Pomier (org.). Identidades da educação ambiental brasileira. Brasília, DF: Ministério do Meio Ambiente, 2004.

LAYRARGUES, Philippe Pomier; LIMA, Gustavo Ferreira da Costa. The Brazilian environmental education macro-political-pedagogical trends. Ambiente \& Sociedade, São Paulo: v. 17, n. 1, p. 23-40, jan./mar. 2014.

LAYTON, David. Science as general education. Trends in Education, London, v. 25, p. 11-15, jan. 1972.

LOPES, Sônia; ROSSO, Sérgio. Bio. v. 1. São Paulo: Saraiva, 2016.

LOUREIRO, Carlos Frederico Bernardo. Educação ambiental crítica: princípios teóricos e metodológicos. Rio de Janeiro: Hotbook, 2002.

MARANDINO, Martha; SELLES, Sandra Escovedo; FERREIRA, Marcia Serra. Ensino de biologia: histórias e práticas em diferentes espaços educativos. São Paulo: Cortez, 2009.

MATTOS, Luiza Maria Abreu de. 0 meio ambiente como um valor cosmopolita no currículo escolar de biologia: comparando livros didáticos do Brasil e da Alemanha. 2019. $234 \mathrm{f}$. Tese (Doutorado em Educação) - Universidade Federal do Rio de Janeiro, Rio de Janeiro, 2019. Disponível em: https://ppge. educacao.ufrj.br/teses2019/tLuiza\%20Maria\%20Abreu\%20de\%20Mattos.pdf. Acesso em: ago. 2017.

MENDONÇA, Patrícia; TRAJBER, Rachel (org.). 0 que fazem as escolas que dizem que fazem educação ambiental. Brasília, DF: Secad: Unesco, 2006.

NÓVOA, António. Modelos de análise em educação comparada: o campo e a carta. In: SOUZA, Donaldo Bello; MARTINEZ, Silvia Alícia (org.). Educação comparada: rotas de além-mar. São Paulo: Xamã, 2009. p. 23-62. 
NÓVOA, António; YARIV-MASHAL, Tali. Comparative research in education: a mode of governance or a historical journey? Comparative Education, London, v. 39, n. 4, p. 423-438, nov. 2003.

OLIVEIRA, Cecília Santos de. Educação ambiental na escola: diálogos com as disciplinas ciências e biologia. 2009. 114 f. Dissertação (Mestrado em Educação) - Universidade Federal do Rio de Janeiro, Rio de Janeiro. 2009.

POPKEWITZ, Thomas. Cosmopolitanism and the age of school reform: science, education, and making society by making the child. New York: Routledge. 2008.

POPKEWITZ, Thomas. Curriculum history, schooling and the history of the present. History of Education, London, v. 40, n. 1, p. 1-19, jan. 2011.

POPKEWITZ, Thomas. Estudios comparados y "pesamiento" comparado inimaginable: la paradoja de la "razon" y sus abyecciones. Espacios en Blanco, Buenos Aires, v. 22, n. 1, p. 17-39. 2012b. (Serie indagaciones).

POPKEWITZ, Thomas. Globalization/regionalization, knowledge, and the educational practices: some notes on comparative strategies for educational research. In: POPKEWITZ, Thomas (org.). Educational knowledge: changing relationships between the state, civil society, and the educational community. Albany: State University of New York Press, 2000. p. 3-27.

POPKEWITZ, Thomas. 0 duplo significado de cosmopolitismo e os estudos comparados de educação. In: COWEN, Robert; KAZAMIAS, Andreas; ULTERHALTER, Elaine (org.). Educação comparada: panorama internacional e perspectivas; volume um. Brasília, DF: Unesco: Capes, 2012a. p. 467-487.

POPKEWITZ, Thomas. Social epistemology, the reason of "reason" and the curriculum studies. Education Policy Analysis Archives, Tempe, v. 22, n. 22, p. 1-23, abr. 2014.

POPKEWITZ, Thomas. The sociology of education as the history of the present: fabrication, difference and abjection. Discourse, London, v. 34, n. 3, p. 439-456, ago. 2012c.

POPKEWITZ, Thomas. Transnational as comparative history: (un)thinking differences in the self and others. In: FUCHS, Eckhardt; ROLDÁN VERA, Eugenia (org.). The transnational in the history of education. Basingstoke: Palgrave Macmillan, 2017. p. 261-291.

SANTOS, André Vitor dos. Investigando a disciplina escolar educação ambiental em Armação dos Búzios, RJ: entre histórias e políticas de currículo. 2010. 132 f. Dissertação (Mestrado em Educação) Universidade Federal do Rio de Janeiro, Rio de Janeiro, 2010.

SAUVÉ, Lucie. Uma cartografia das correntes em educação ambiental. In: SATO, Michèle; CARVALHO, Isabel (org.). Educação ambiental: pesquisa e desafios. Porto Alegre: Artmed, 2005. p. 17-44.

SCHLEICHER, Klaus. Trends and current state of environmental education in Germany. In: BOS, Wilfried; LERMAN, Rainer H. (org.). Reflections on educational Achievement. New York: Waxman, 1995. p. 230-255. 
SCHRIEWER, Jürgen. Aceitando os desafios da complexidade: metodologia da educação comparada em transição. In: SOUZA, Donaldo Bello de; MARTINEZ, Sílvia Alícia (org.). Educação comparada: rotas de além-mar. São Paulo: Xamã, 2009. p. 63-105.

SCHRIEWER, Jürgen. The method of comparison and the need for externalization: methodological and sociological conceptions. Theories and Methods in Comparative Education, Frankfurt, v. 17. p. 25-83, 1992.

SELLES, Sandra Escovedo; FERREIRA, Marcia Serra. Disciplina escolar Biologia: entre a retórica unificadora e as questões sociais. In: MARANDINO, Mrtha et al. (org.). Ensino de biologia: conhecimentos e valores em disputa. Niterói: UFF, 2005. p. 50-62.

SORRENTINO, Marcos. Educação ambiental e universidade: um estudo de caso. 1995. Tese (Doutorado em Educação) - Programa de Pós-Graduação em Educação, Universidade de São Paulo, São Paulo, 1995.

UNTERBRUNER, Ulrike. Umweltbildung. In: GROPENGIEßER, Harald; HARMS, Ute; KATTMANN, Ulrich (org.). Fachdidaktik biologie. Köln: Aulis. 2016. p. 169-190.

VASCONCELOS, Matheus de Almeida; GOMES, Maria Margarida. Ecologia: investigando aspectos constitutivos do currículo de biologia em livros didáticos. In: ENCONTRO NACIONAL DE PESQUISA EM EDUCAÇÃO EM CIÊNCIAS (ENPEC), 8., 2011, Campinas. Anais... Campinas: Enpec, 2011. p. 1-11.

Recebido em: 16.10.2019

Revisado em: 12.05.2020

Aprovado em: 30.06 .2020

Luiza Maria Abreu de Mattos é professora de ciências e biologia, doutora em educação pela Universidade Federal do Rio de Janeiro (UFRJ), participa do grupo de estudos "Currículos escolares, ensino de ciências e materiais didáticos" no LaNEC/UFRJ - Laboratório do Núcleo de Estudos de Currículo.

Maria Margarida Gomes é professora associada do Departamento de Didática da Faculdade de Educação e do Programa de Pós-Graduação em Educação da UFRJ. Coordena o Grupo de Estudos "Currículos escolares, ensino de ciências e materiais didáticos", no LaNEC/UFRJ Laboratório do Núcleo de Estudos de Currículo. 